\title{
The role of IT\&C tools in Managing Vocational Education and Training Projects co-financed by the European Social Fund
}

\author{
Alexandru Capatina \\ Faculty of Economics and Business Administration \\ Dunarea de Jos University of Galati, Romania \\ George Schin \\ Faculty of Juridical, Social and Political Sciences \\ Dunarea de Jos University of Galati, Romania,
}

\begin{abstract}
This paper emphasizes practical ways to manage Vocational Education and Training (VET) projects through IT\&C tools. VET projects aim to equip people with knowledge and competences required in particular occupations on the labour market. In this way, as Romania has to recover significant gaps in hat concern the implementation of highly effective VET programmes, European Social Fund represents a huge opportunity for financing such kind of projects. The goal of the paper consists of revealing the project management capabilities provided by Microsoft Project and Balanced Scorecard Designer software, in a real project context. The presentation of a VET project processes, such as planning, assigning resources, budgeting and performance assessment, leads to a comprehensive overview of IT\&C contributions to effective project management.
\end{abstract}

Keywords: Vocational Education and Training, European projects, project management, project performance, information technology

\section{THE MANAGEMENT OF VOCATIONAL EDUCATION AND TRAINING PROJECTS}

Adults, the persons that have reached the age for getting into an employment relationship, have access to vocational training. Adult vocational training is organized through programs of initiation, qualification, requalification, specialization, having as purpose the following:

* Initiation - acquiring one or more competencies specific to a qualification;

* The qualification, respectively requalification - acquiring an assembly of vocational competencies allowing an individual to develop activities specific to one or more profession;

* Skills upgrade, respectively specialization - development or completion of knowledge, skills or vocational competencies within the same qualification, acquirement of new competencies, of key or new technical competencies.

Adult initial training ensures the training necessary for acquiring the minimum vocational competencies necessary for obtaining a job.

Vocational Education and Training (VET) comprises all more or less organised or structured activities whether or not they lead to a recognised qualification which aim to develop knowledge, skills and competences that are necessary in order to perform a job (Descy \& Tessaring, 2001). 
The vocational training of adults is subsequent to initial training and it ensures either the development of vocational competencies already acquired, or acquiring new competencies. Adult vocational training is managed by the National Center for Vocational Training for Adults (CNFPA).

The objective of this major intervention domain is to improve the access and participation to continuous vocational training programmes, facilitating employees' qualification or requalification, according to the information provided on the website dedicated to the management of activities co-financed by European Social Fund in Romania http://www.fonduri-ue.ro. The operational objective of the Major intervention domain 2.3 aimed through this appeal is "Promoting the access of employees to VET programmes, so that they obtain full qualification". The operations within the Major intervention domain 2.3, for your reference, relevant for this request for proposal of projects, are the following: Delivery of qualification and requalification courses to the employees; Providing support and incentives to employees in order to participate to VET; Employees' support for validating the previously acquired knowledge; Granting facilities for "hard to reach" individuals (unskilled or low skilled adult population).

Due to the diversity of goals, national Vocational Education and Training projects are mostly a heterogeneous mix of features within and outside the general education system (Bosch \& Charest, 2009). Comparative studies of higher education and vocational education and training systems across and within countries should, therefore, be aware of specific national origins, unique developmental trajectories, and the relationship between the two as these react to internationalization (Powell \& Solga, 2010).

In Romania, the vocational training system has been organised as a network of national, local and sectoral structures of the authorities in charge, according to the information provided on the website http://eurofound.europa.eu/. The system, however, does not operate at maximum potential for lack of financial resources - but the European Social Fund provides lots of opportunities in this way. An interesting research conducted by Malamud \& Pop-Eleches (2010) outline the relative benefits of general education and vocational training in the context of a transition economy that experienced major technological and institutional change.

Romania have many gaps to recover in what concerns VET programmes. In this way, learning from vocational education and training (VET) systems in the UK (Cuddy \& Leney, 2005), which tend to be highly competitive, could be considered as an appropriate strategy for Romanian VET system, based on strengths and challenges in the emerging systems of lifelong learning.

\section{Configuration of activities specific to a continuous vocational education and training project, co-financed through ESF}

Choosing the right software to manage projects represents a challenging task for any project manager. The results of a survey showed that most respondents used only a small number of methods, tools and techniques with project management software and Gantt charts being the most widely used aids (White \& Fortune, 2002).

The configuration of the activities specific to a vocational education and training project, cofinanced through the European Social Fund - ESF, in Gantt display, represents the first initiative within project IT management. 
In order to achieve a simulation of the management of a vocational training project co-financed through ESF, with the help of Microsoft Project software, I considered pertinent to configure the following main activities:

- Purchase of materials, consumables and equipments;

- Selection and information of the target group;

- Development of vocational training activities;

- Develop acknowledging campaigns;

- Evaluation of project's results;

- Information and publicity for the project.

The projects that propose to include in the target group unskilled employees for the domain in which they work for, or with a low skill level, they will receive a supplementary score. Considering the fact that the eligible continuous vocational training activities within the actual request for proposal of projects are exclusively those meant for qualification and/or requalification, we remind that the vocational training that aims at the initiation or specialization / skills upgrade of employees or managers is not eligible for financing within the major intervention domain 2.3 "Access and participation in Vocational Education and Training".

Within this activity, the scope consists in supporting the employees, for their qualification/requalification through: participation to VET authorized programmes, developed in Romania or in the European Union, for acquiring a (new) qualification, certifying the competencies acquired within VET programmes; validation and certification within the authorized centers of evaluation and certification of the vocational competencies acquired in contexts other than formal ones; information on the opportunities of qualification/requalification of employed persons; experience exchange and dissemination of good practices, as support elements for the vocational training programmes for qualification / requalification.

The development of the vocational education and training activities involves a set of sub activities focused on:

* Issue continuous vocational education and training programmes for the qualification and/or requalification of employees from eligible economic sectors;

* Issuing support materials for learning, for the implemented vocational training programmes; authorization in order to provide continuous vocational training programmes for the qualification and/or requalification of employees from eligible economic sectors;

* Provide continuous vocational training programmes for qualification and/or requalification of employees from eligible economic sectors.

The insufficient development of the learning acquisitions' transfer mechanisms obtained between different contexts of learning, limit the possibilities of the population, especially the adult population, to obtain formal accreditation of the competencies cumulated on the labor market and to reenter in the formal education system. Also, at the level of issuing the policies, it is necessary a better coherence between the policies from education area, of initial vocational training and continuous vocational training.

The validation of the obtained learning acquisition, a better correlation between initial vocational education and training, and vocational training (VET), improving the definition and 
transparency of professional qualifications are aspects that will be approached through developing and implementing the National Qualification Framework (NQF).

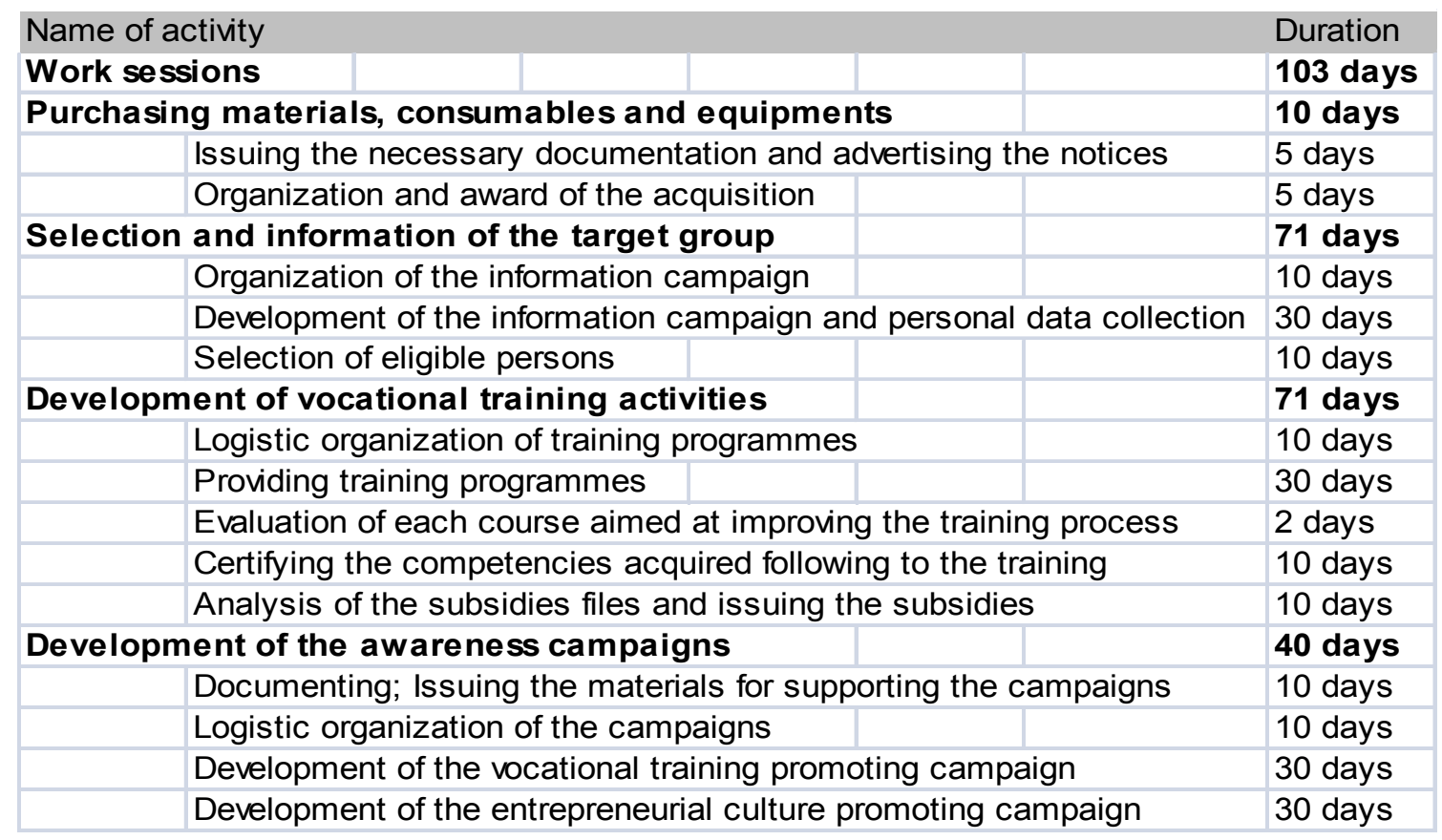

Figure no. 1 - Project's Activities Organization

Immediate performance (output) indicators highlight the numbers of participants to VET programmes (qualification and requalification) - there will be quantified the number of persons that participate to continuous vocational training programmes (qualification and requalification) that ensures either acquiring new competencies, or development of already acquired vocational competencies for the adult population. Also, it is taken into consideration the participants' share to certified VET programmes - it will be estimated the percentage report between the number of persons that have obtained a certification of qualification following to participating to VET (qualification) and the total number of participants to continuous vocational training programmes (numeric value mentioned at the first output indicator).

\section{Configuration of resources and establishing the budget of the project}

Any managerial project involved three categories of resources: human, equipment and materials. Microsoft Project application offers to its users the possibility to configure the resources necessary for fulfilling the objectives of a managerial project in Resource Sheet screen, concentrating on two aspects of the resources: availability and cost. The availability determines the moment and measure to which a certain resource can contribute to achieving an activity, and the costs refer to the amount that would be necessary for the payment of the respective resource.

In the project model chosen in this case study, the involved human resources are represented by the project management and implementation team members, 10 persons in number, all volunteers. Besides the human resources, a series of material resources have been configured. The degree of allocation in the project is designated in "Max Units" field, and the fee at which they are paid for the standard work time and for supplementary working hours is evidenced in "Std. Rate" and "Ovt. Rate" fields. The equipment resources (hardware components interconnected in the network, the components of the information technology system aimed at training activities management, laptops) create the infrastructure necessary for developing the 
actions provided in the project, while the material resources (electricity, consumables, promotional leaflets) ensure the support of developing the activities. In case of equipment resources, the costs are inserted in Cost/Use fields, and for material resources, unit costs are evidenced (figure no. 3.7)

Resources allocation supposes their assignment to activities with the purpose of fulfilling the objectives. One resource or more can be assigned to an activity, no matter the category it is part of. At the same time with allocating more resources to an activity, the time frame corresponding to it changes, as Microsoft Project uses a method named effort-driven scheduling, which is based on the principle that the work necessary for an activity remains constant, no matter the number of resources allocated, but the time period will be diminished as supplementary resources are added.

Resources allocation is done with the help of Assign Resources function existing in Tools menu. Any allocation supposes assigning a project for the human resources and equipment resources and a quantity expressed in the unit of measurement established in Resource Sheet screen for material resources. We must mention the fact that allocations of resources cannot be achieved but only in case of sub-activities, due to the fact that they represent the components of complex activities.

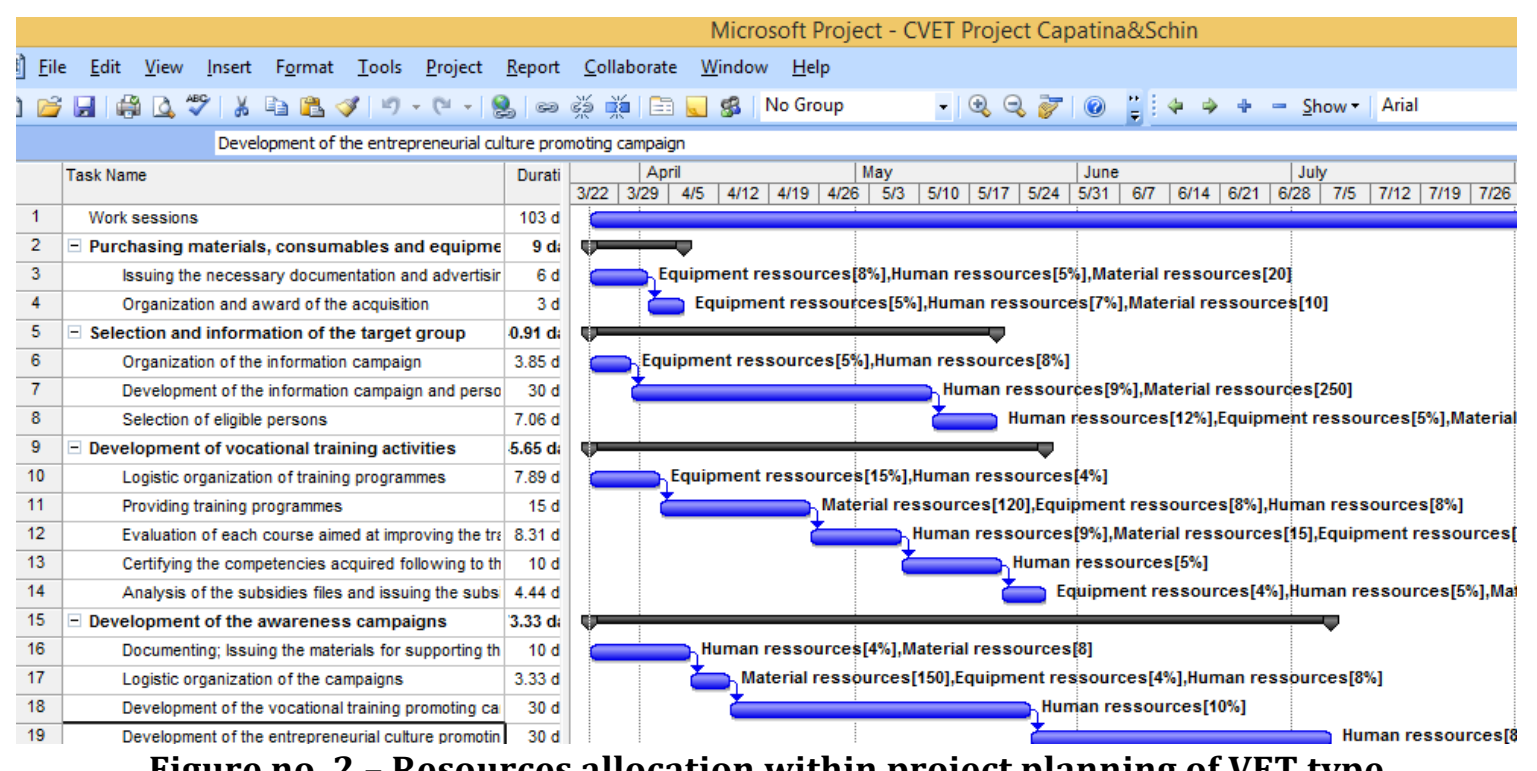

Figure no. 2 - Resources allocation within project planning of VET type

In many projects, the cost of resources represents the main factor that limits the objectives aimed. The project manager can view the total costs split activity wise, by accessing View menu and selecting the option Table: Cost from Microsoft Project. (Figure no. 3) 


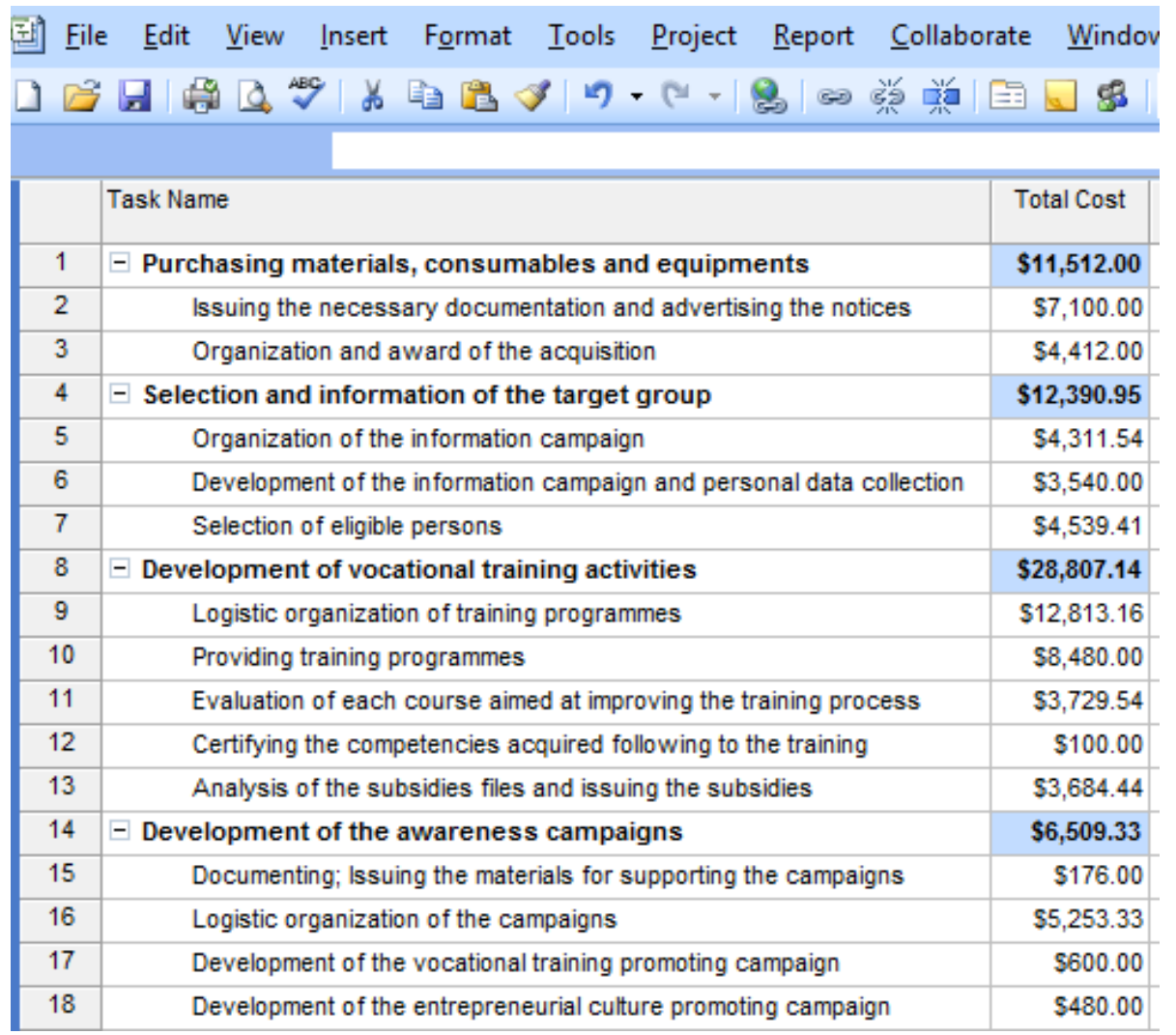

Figure no. 3 - Budgeting report corresponding to the activities from VET project

\section{Integrating Balanced Scorecard Designer software in assessing the performance indicators of a VET project}

Turn to the Internet, searching on BSC software easily allow a person to find out in excess of 30 different organizations all of whom are willing to offer you BSC applications (Marr \& Neely, 2003). For the goal of this current research, we adopted Balanced Scorecard Designer software, developed by the American company AKS LABS that simplifies the processes corresponding to the creation and IT management of the balanced dashboard (Balanced Scorecard).

Balanced Scorecard Designer generates concise reports characterized by a set of measures that have connection with the performance of a project.

The software allows creating a set of key indicators that can be grouped categories wise; relative importance coefficients are associated to each category and objective defined by the deciding factor, according to the importance granted to them. For each indicator, a minimum and maximum value is established, so that the selected optimization strategy will be able to determine the calculation of the performance management indicators.

We have considered convenient to highlight the integration of the Balanced Scorecard Designer software application, in case of assessing the output indicators and the result in the case of a project of "vocational education and training for employees" type, from the priority axis 2 „The correlation of lifelong learning with labor market”, major intervention domain 2.3 „Access and participation in VET".

\section{Immediate performance (output) Indicators}

The number of participants to VET programmes (qualification and requalification) - it will be quantified the number of persons that participate to continuous vocational training 
programmes (qualification and requalification) that ensures either acquiring new competencies, or development of already acquired vocational competencies for the adult population.

The number of persons assisted for validation and certification of the competencies acquired in non-formal contexts - there will be quantified the number of employees, individualized according to their Personal Identification Number, whose knowledge/abilities/competencies will be subject to a process of validation and certification, within the project, according to the provisions of the national legislation in force, regarding the validation and certification of vocational competencies acquired in contexts other than formal ones.

\section{Result indicators}

The ratio of certified participants to VET - it will be estimated the percentage report between the number of persons that have obtained a certificate of qualification following to the participation to VET (qualification) and the total number of participants to continuous vocational training programmes (numerical value given by the first output indicator).

The number of certified participants to training - continuous vocational training - there will be estimated the number of employees, individualized according to their Personal Identification Number, who will obtain a certificate of qualification following to participating to continuous vocational training programmes (qualification and requalification)

The intervals of optimization, as well as the real value of the indicators associated to the "Immediate performance (output) indicators" dimension are presented in table no. 1.

Table no. 1: Indicators associated to the "Immediate performance (output) indicators" dimension

\begin{tabular}{|l|c|c|c|c|}
\hline \multicolumn{1}{|c|}{ Indicators } & $\begin{array}{c}\text { Real } \\
\text { value }\end{array}$ & $\begin{array}{c}\text { Minimum } \\
\text { value }\end{array}$ & $\begin{array}{c}\text { Maximum } \\
\text { value }\end{array}$ & $\begin{array}{c}\text { Coefficient } \\
\text { of } \\
\text { importance }\end{array}$ \\
\hline $\begin{array}{l}\text { The number of participants to VET } \\
\text { programmes }\end{array}$ & $\mathbf{4 5 0}$ & 200 & 500 & $\mathbf{5}$ \\
\hline $\begin{array}{l}\text { The number of persons assisted for } \\
\text { validation and certification of the } \\
\text { competencies acquired in non- } \\
\text { formal contexts }\end{array}$ & $\mathbf{1 2 0}$ & 85 & 150 & $\mathbf{5}$ \\
\hline
\end{tabular}

The optimization intervals, as well as the real value of the indicators associated to "Result indicators" dimension, are presented in table no. 2.

Table no. 2: Indicators associated to "Result indicators" dimension

\begin{tabular}{|l|c|c|c|c|}
\hline \multicolumn{1}{|c|}{ Indicators } & $\begin{array}{c}\text { Real } \\
\text { value }\end{array}$ & $\begin{array}{c}\text { Minimum } \\
\text { value }\end{array}$ & $\begin{array}{c}\text { Maximum } \\
\text { value }\end{array}$ & $\begin{array}{c}\text { Coefficient } \\
\text { of } \\
\text { importance }\end{array}$ \\
\hline $\begin{array}{l}\text { The ratio of certified participants to } \\
\text { VET }\end{array}$ & $\mathbf{8 1}$ & 0 & 100 & $\mathbf{5}$ \\
\hline $\begin{array}{l}\text { The number of certified } \\
\text { participants to training }\end{array}$ & $\mathbf{3 2 5}$ & 200 & 350 & $\mathbf{5}$ \\
\hline
\end{tabular}


The introduction of these four indicators, grouped according to these 2 perspectives in the operational base of Balanced Scorecard Designer application.

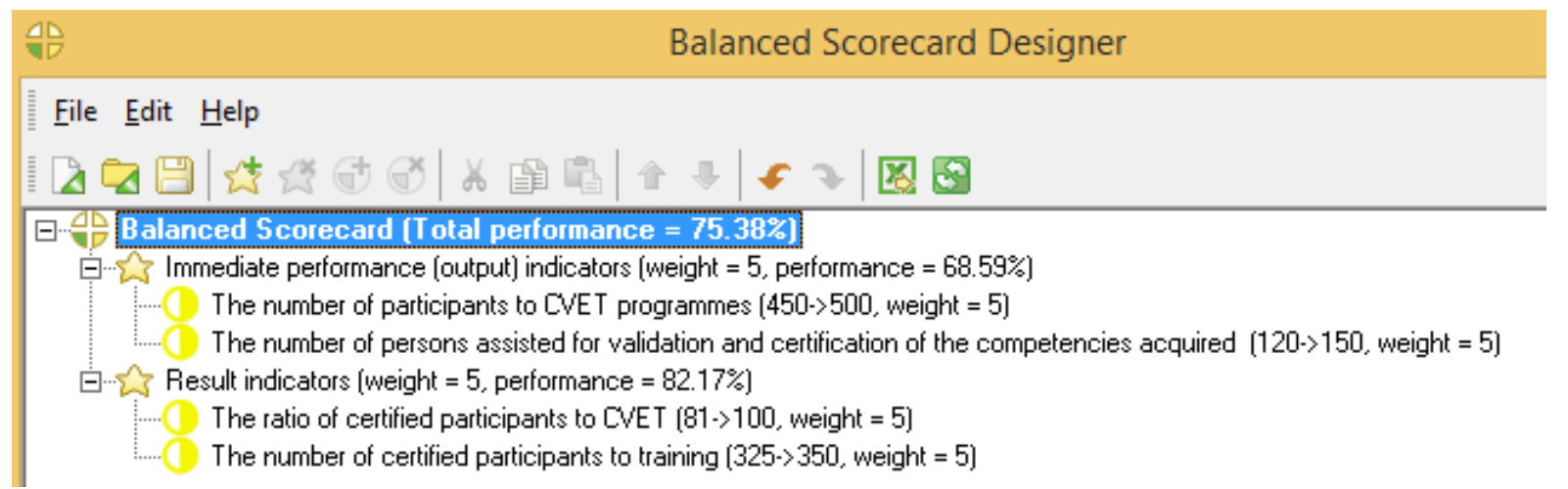

Figure no. 4 - Determining the performance of a VET project through the point of view of evaluating output and result indicators

The optimization function implemented in Balanced Scorecard Designer program illustrates the method of calculating the contribution of each indicator to the global performance of the project and it depends on the objective aimed for each and every case (minimization, respectively maximization).

In case of a maximization objective, the optimization function supposes the following formula:

Maximize RP $=$ MP*Score $/$ Max

In which: RP - real performance; MP - actual value of the indicated analyzed.

In case of a minimization objective, the optimization function supposes the following formula:

Minimize RP $=$ MP*Score $/$ Min

In the context of this project example, we have applied the maximization function for those four indicators.

The value of global performance proves a remarkable success rate of VET project (75.38\%), as it is considered that a project has a satisfying success rate if the global performance value is situated between $50 \%$ and $60 \%$, and the values that exceed this threshold signify an important success of the project.

\section{CONCLUDING REMARKS}

Applying the projects' management functions gives to the users of Microsoft Project software the possibility to plan and efficiently manage a VET project and it ensures the optimization of the balance between the three specific sides of management's triangle through projects: objectives, resources and budget. Organizing the activities specific to a project, the quick estimation of the activities duration following to resources allocation, displaying the resources over-allocation situations and the possibility to solve them, generating some reports where there can be viewed the project costs split activities and resources wise, the existence of the filtering and data grouping functions, the on-line collaboration function activated in Microsoft Project Server version represents the main strong points of Microsoft Project application that managed to come into prominence on the market of IT solutions aimed for the management of the organizations.

We also observed that the greatest contribution to achieving the global performance of the VET project is due to the result indicators (82.17\%), while output indicators had a performance of $68.59 \%$. In conclusion, using this software allows the ranking of the performance indicators 
associated to a project, according to the contribution of each person to achieving the performance of the project.

\section{References}

Bosch, G., \& Charest, J. (Eds.). (2009). Vocational training: international perspectives. Routledge.

Cuddy, N., \& Leney, T. (2005). Vocational education and training in the United Kingdom, available at http://www.cedefop.europa.eu/EN/Files/5159_en.pdf

Descy, P., \& Tessaring, M. (2001). Training and Learning for Competence: Second Report on Vocational Training Research in Europe. Executive Summary. CEDEFOP Reference Series. CEDEFOP, PO Box 22427, Thessaloniki, GR55102 Greece.

Malamud, O., \& Pop-Eleches, C. (2010). General education versus vocational training: Evidence from an economy in transition. The review of economics and statistics, 92(1), 43-60.

Marr, B., \& Neely, A. (2003). Automating the Balanced Scorecard-selection criteria to identify appropriate software applications. Measuring Business Excellence, 7(3), 29-36.

Powell, J. J., \& Solga, H. (2010). Analyzing the nexus of higher education and vocational training in Europe: a comparative-institutional framework. Studies in Higher Education, 35(6), 705-721.

White, D., \& Fortune, J. (2002). Current practice in project management-An empirical study. International journal of project management, 20(1), 1-11.

http://www.fonduri-ue.ro/posdru/images/doc2014/ghid2.3z.pdf

http://eurofound.europa.eu/de/observatories/eurwork/erm/comparative-information/nationalcontributions/romania/romania-collective-bargaining-and-continuous-vocational-training 